\title{
METASTATIC ADENOCARCINOMA OF THE OPTIC NERVE-HEAD AND ADJACENT RETINA*
}

\author{
BY \\ F. J. CHERINGTON \\ Ophthalmic Institution, Glasgow
}

Metastatic tumours in the optic nerve and its sheaths are very rare, and only a few cases are to be found in the literature (Duke-Elder, 1940). The most common tumour of this type is metastatic carcinoma and the deposit occurs in the sheaths of the nerve more frequently than in the nerve itself. Cases involving the nerve substance and retina have been described by several authors.

Elschnig (1891) reported a metastasis in the nerve secondary to a bronchial carcinoma, and Holden (1902) and McDannald and Payne (1934) noted similar deposits in carcinoma of the breast. Davis (1932) recorded an original focus at the disc-again secondary to carcinoma of the breast, and Sattler (1926) described an eye in which the whole retina was replaced by new growth in a case of carcinoma of the pancreas, the original metastatic site being at the optic disc.

The following case illustrates an early stage in the development of a lesion such as that described by Sattler.

\section{Case Report}

A housewife aged 62 attended the Ophthalmic Institution, Glasgow Royal Infirmary, on March 1, 1960, having noticed blurring of vision in the left eye for one month.

Examination.-The patient did not look ill but had been attending a medical outpatient department at intervals during 1959 for treatment of early congestive cardiac failure. A diagnosis of aortic stenosis had been made and she had responded well to oral Saluric.

LEFT EYE.-The visual acuity was $6 / 24$ with $+1 \mathrm{D}$ sph. The pupil reacted sluggishly to light but external examination showed no other abnormality. The media were clear.

The fundus appearance was striking. Arising from the optic disc there was a somewhat pedunculated white mass with punctate haemorrhages on its surface. In the adjoining retina larger irregular areas of haemorrhage were seen, arranged, for the most part, in a ring around the disc about $2 \mathrm{~mm}$. from its margin. There was congestion of the retinal veins especially temporally and the vessels appeared to be carried forward by the mass (Fig. 1, overleaf). The ocular tension was not raised.

* Received for publication May 9, 1960. 


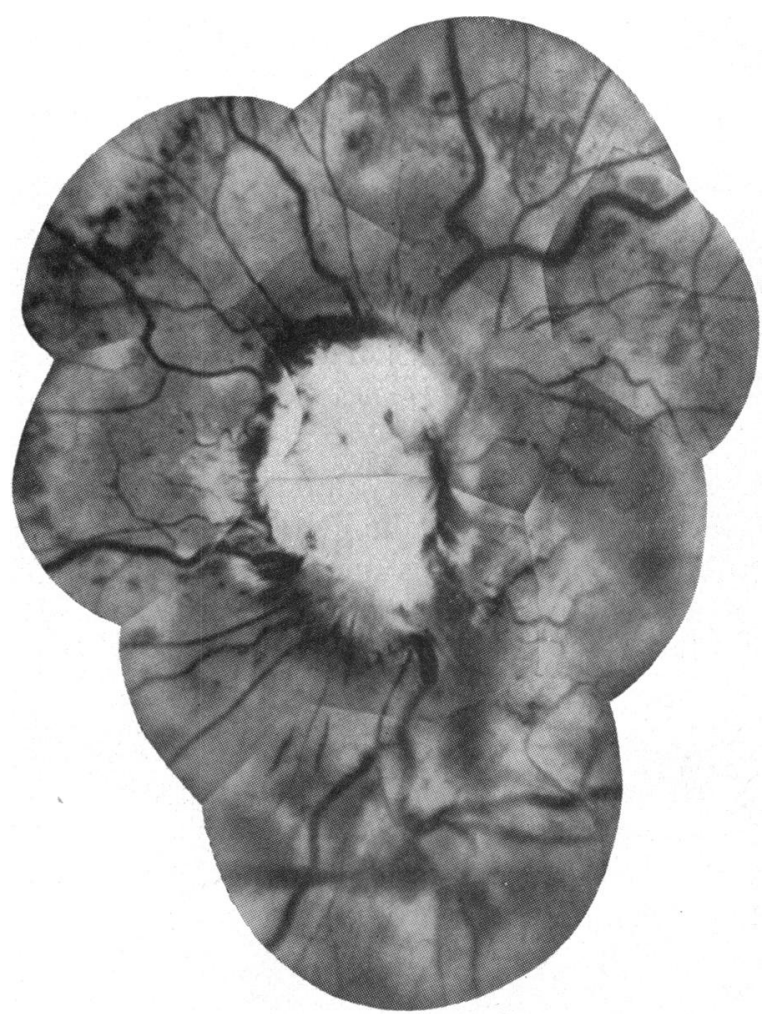

Fig. 1.-Fundus photograph of left optic disc on March 5, 1960.

RIGHT EYE.-The visual acuity was $6 / 6$ with $+1 \mathrm{D}$ sph. No abnormality was found.

Progress.-The patient entered hospital on March 4, 1960, for investigation. Blood Wassermann and Kahn reactions and the Mantoux test were negative. The blood picture was normal but the erythrocyte sedimentation rate was consistently raised, the average readings being $33 \mathrm{~mm}$. in the first hour and $64 \mathrm{~mm}$. in the second. Apart from an aortic systolic bruit and cardiac enlargement, no abnormality was found on clinical examination.

$X$-rays of the skull and optic foramina showed no abnormality, but chest films (including tomographs) disclosed a lesion solid in the right lower lobe. The appearance suggested a primary bronchial carcinoma. In addition, a probable secondary deposit and pathological fracture were noted at the lateral extremity of the right clavicle.

On March 7, 1960, the patient coughed up a quantity of blood-stained sputum, but subsequent sputa were free of blood and smears for tubercle bacilli gave negative results.

Repeated examination of the left fundus showed the mass to be increasing rapidly in size. Enucleation of the left eye was carried out on March 12,1960, and the patient was afterwards transferred to a medical unit.

Pathological Report: "Situated in the optic nerve-head and the peripapillary retina, there are numerous but isolated clumps of small round hyperchromatic cells showing a definite acinar formation. The retina in the region of the disc is oedematous and disorganized and a haemorrhagic albuminous subretinal exudate is present." 
Diagnosis.-Secondary adenocarcinoma of optic nerve and retina (Figs 2 and 3).

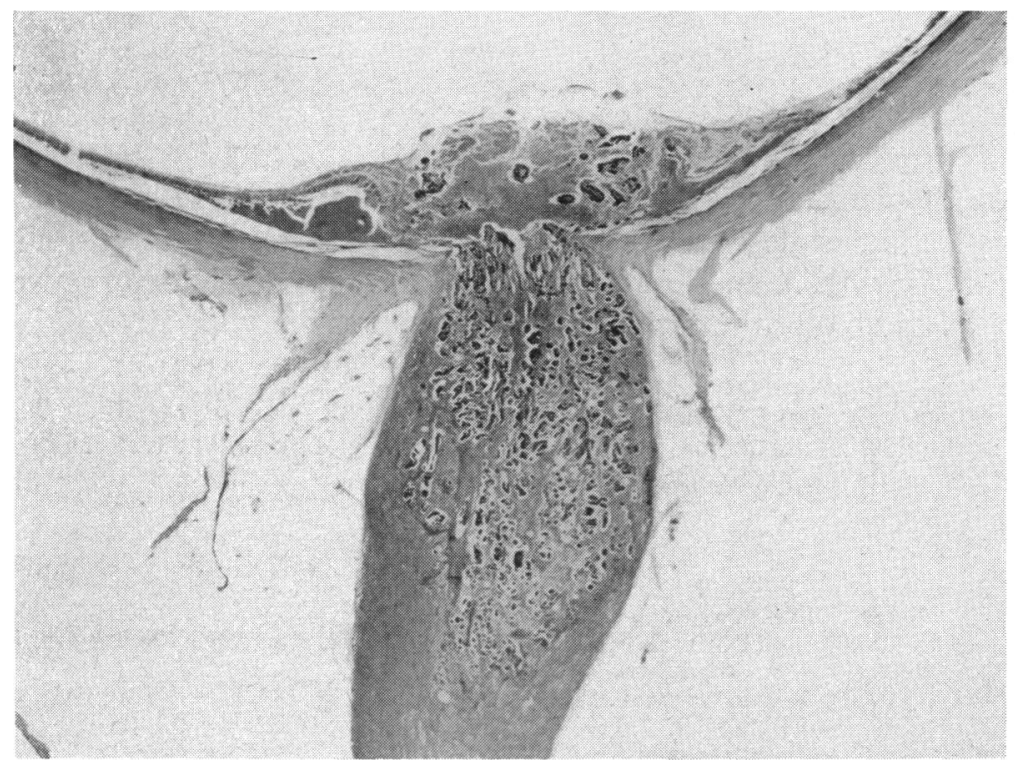

Fig. 2.-Low-power view of section, showing the mass in the optic cup and malignant cells in the nerve head. $\times 10$.



Fig. 3.-High-power view, showing a typical clump of cells in the nerve. The acinar arrangement is well seen. $\times 500$.

\section{Discussion}

The case is of interest in view of the rarity of metastatic carcinoma of the optic nerve, especially at the disc.

In the absence of unequivocal radiological findings it is likely that the lesion would have been diagnosed clinically as a primary intra-ocular growth. Glioma, neurinoma, or malignant melanoma (either of the disc or of the juxtapapillary choroid) would have been considered likely. 
In this instance the $x$-ray findings were paramount in making the correct diagnosis, subsequently confirmed by histological examination of the sections.

\section{Summary}

A case of metastatic adenocarcinoma of the optic nerve-head and juxtapapillary retina is described and the histological appearances illustrated. A primary growth in the lung and a probable secondary deposit were discovered by radiological examination.

I wish to thank Dr. Janet F. Steel for permission to publish this case, Mr. J. C. Watt of the Tennent Institute of Ophthalmology, Glasgow, for the photographs, and the Institute of Ophthalmology, London, for the pathological report.

\section{REFERENCES}

DAVIS, W. T. (1932). Arch. Ophthal. (Chicago), 8, 226.

DUKE-ELDER, S. (1940). "Text-book of Ophthalmology", vol. 3, p. 3098 . Kimpton, London. ELSCHNIG, A. (1891). Arch. Augenheilk., 22, 149.

HoLDEN, W. A. (1902). Arch. Ophthal. (N.Y.), 31, 427.

McDannald, C. E., and Payne, B. F. (1934). Arch. Ophthal. (Chicago), 12, 86.

SATTLER, H. (1926). "Die bösartigen Geschwülste des Auges". Hirzel, Leipzig. 